\title{
Study on the Development Process and Improvement Countermeasures of Waste Classification in China
}

\author{
XiaoJun $\mathrm{Li}^{1}$, Ying Wang ${ }^{2}$, Jin $\mathrm{Xu}^{*}$ \\ ${ }^{1}$ Industrial engineering, College of management, Tianjin University of Technology, 300380, Tianjin, China \\ ${ }^{2}$ Industrial engineering, College of management, Tianjin University of Technology, 300380, Tianjin, China \\ *Environmental Engineering, School of Environmental Science and Safety Engineering, Tianjin University of Technology, 300380 , \\ Tianjin, China
}

\begin{abstract}
In order to respond to the national ecological policy, to ensure the improvement of the urban ecological environment, the prevention and control of solid waste pollution, and the protection of public health and safety, the construction of ecological civilization is put in the primary development position. Therefore, the overall planning and reasonable deployment of the classified collection and treatment of urban domestic waste can effectively achieve the goal of secondary utilization of urban waste. The article has basically combed the history of garbage classification in my country, analyzed the problems existing in China garbage classification in the past, expounded the latest progress, and put forward some suggestions for the implementation of garbage classification in my country in the new era.
\end{abstract}

\section{Introduction}

Garbage classification is an important means to maintain and protect the environment. Through the management of garbage classification, the problem of urban garbage siege can be effectively solved. The "Implementation Plan for the Domestic Waste Classification System" clearly sets out the issue of domestic waste classification. Urban management and urban services are also continuously improved. In order to jointly create a suitable living environment for the people, all departments, regions, and streets in China Actively carry out the pilot work of domestic waste classification, the coverage rate of domestic waste classification collection has reached more than $90 \%$, and the recycling rate has reached $35 \%$. However, the effects of waste classification management are not very significant, such as: short persistence, insufficient coverage, poor personnel quality, etc. These are the areas that need to be improved for further improvement of domestic waste classification in China.

With the acceleration of urbanization and the promotion of the integration of urban and rural sanitation, the urban population continues to grow, and the amount of domestic waste increases sharply. The promotion of domestic waste classification in our country can not only reduce environmental pollution problems, but also promote the development of social and ecological benefits. At present, most cities in China have implemented domestic waste classification policies. The implementation of waste classification can reduce waste output while achieving resource conservation and reuse goals. Garbage classification can also achieve the reduction and resource utilization in the Solid Waste
Pollution Prevention Law. And the requirements of the principle of harmlessness.

\section{Historical lessons of garbage classification in China}

The promotion of the classification of urban domestic waste in my country has lasted for many years. In the mid1990s, some developed areas such as Beijing, Shanghai, and Hangzhou started their own waste classification. In order to reduce the amount of public garbage in China and promote the harmless treatment and recycling of garbage, in 2000, China drew lessons from the advanced experience of western developed countries such as Japan, the United States and Germany in garbage classification and recycling, and formally issued the Notice on Announcing Pilot Cities for Domestic Garbage Classification and Collection. Eight cities including Beijing, Shanghai, Guangzhou, Nanjing and Guilin were taken as pilot cities [1] for domestic garbage classification and collection, which officially kicked off the pilot work of domestic garbage classification and collection. The early behavior of garbage sorting has led to certain improvements in public environmental sanitation, but the reduction, harmlessness, and recycling of garbage are still far from the original idea. The main problems are as follows:

\subsection{Garbage classification is unscientific and cannot be effectively identified}

Classified trash can is an early domestic garbage disposal method in China, classified trash can is mainly divided into two simple categories, one is recyclable and the other

\footnotetext{
* Corresponding author: xujinhb@email.tjut.edu.cn
} 
is non-recyclable. From the original intention of implementation, simple classification is conducive to the rapid promotion of garbage classification activities, but contrary to expectations, there are many problems in the actual garbage delivery process. First, ordinary people do not know how to distinguish between recyclable garbage and non-recyclable garbage, which directly leads to classified garbage bins becoming furnishings in real life. Second, in addition to the problems in the way people deal with garbage, the sanitation department, as the direct management and recycling department of garbage, dumped classified garbage cans into garbage trucks without discrimination, and garbage classification became nominal ${ }^{[2]}$.

\subsection{The organization is uncoordinated, and the social cost of garbage classification is high}

The recycling of used batteries was originally a garbage classification project with relatively clear objects and easy results, but from the effect of implementation for many years, its effect was not obvious. The state advocates centralized recycling of used batteries in supermarkets, convenience stores and street communities. In the initial period of time, many ordinary people actively participated in the recycling of used batteries. Due to the large number of waste batteries, the mismatch of waste periods, the time-consuming collection of ordinary people, and the centralized collection of supermarkets and street institutions, the process is cumbersome. From the whole recycling system of used batteries, the time cost and economic cost are uneconomical, no matter from the ordinary people at the source or from the centralized recycling institutions. Therefore, after the initial promotion, the enthusiasm of the masses and institutions was exhausted, and the recycling of used batteries fell into a stagnant stage again. It can be seen that without the support of the complete reuse industrial system of acquisition, transportation, sales, processing and finished products market, waste sorting can not produce economic benefits, but can only be a waste of money and labour.

\subsection{Decisions lack rationality and people's participation is low}

Plastic bags bring great convenience to the lives of ordinary people. But at the same time, plastic bags do great harm to the natural ecological environment. Since 2008, China began to implement the plastic limit order. By speeding up the popularization of paper bags and implementing policies such as paid use of plastic bags, we tried to reduce the utilization rate of plastic bags, but the use of plastic bags was increasing. The basic reason is that the substitutability of economic behavior can't offset the increased time cost of ordinary people, which leads ordinary people to use plastic bags even if they spend more money and pollute the environment. Finally, the plastic limit order completely goes against the original intention.

\section{The latest progress of garbage classification in China in the new period}

Since the 18th National Congress of the Communist Party of China, China has entered a new period of social and economic development, and the construction of ecological civilization has entered a new climax. Garbage classification, as an important part of it, has once again attracted the attention of the whole society.

\subsection{National top-level design}

First, some relevant administrative regulations are issued. In December, 2016, the meeting of the Central Financial and Economic Leading Group decided to implement the garbage classification system nationwide. In March, 2017, the Implementation Plan of Domestic Waste Classification System was officially promulgated, which required the gradual construction of a garbage classification system based on the rule of law, promoted by the government, participated by the whole people, coordinated urban and rural areas and adapted to local conditions, accelerated the establishment of a garbage disposal system with classified delivery, classified collection, classified transportation and classified treatment, and strived to improve the coverage of the garbage classification system. In June 2019 , in order to further speed up the implementation of the waste sorting system, enhance the disposal and prevention of solid waste, and improve the social and ecological environment of urban and rural areas in China, the first revised draft of China's Law on Prevention and Control of Environmental Pollution by Solid Waste was officially promulgated and submitted to the Standing Committee of the National People's Congress for deliberation.

\subsection{Local agency response}

In response to the state's guidance on waste sorting, many provinces, cities and public institutions in China have formulated local implementation plans for waste sorting in recent years. For example, in July 2019, Xinyang City, Henan Province issued the Implementation Plan of Domestic Waste Classification in Xinyang City in 2019, which proposed to implement garbage classification in three stages, speed up the allocation of necessary garbage classification facilities and equipment, promote regional pilot projects, give play to the demonstration effect, and actively promote the popularization and publicity and education of domestic waste classification knowledge. In December, 2019, Guangdong Province issued the "Guidelines for Classification of Urban Domestic Waste in Guangdong Province", which clearly stated that it is necessary to gradually establish a collection system of domestic waste treatment fees based on classified pricing and metering charges. Since 2020, Tianjin, Hebei, Hunan and other provinces have successively issued implementation plans for domestic waste classification. For public institutions, the State Administration of State Organs Affairs issued the Reference Standard for Evaluation of Domestic Waste Classification in Public 
Institutions in September, 2019, emphasizing the pioneering demonstration role, taking the lead in implementing domestic waste classification in public institutions across the country, and setting a model for garbage classification in other enterprises and institutions. At present, 46 key cities in China, mainly municipalities directly under the central government, provincial capitals and cities with separate plans, have carried out the pilot work of garbage classification, which started gradually from point to area, and some progress has been made in garbage classification in various ${ }^{[3]}$ places.

\section{Thoughts on China's waste sorting project in the new period}

From the above historical experience analysis and the latest progress ${ }^{[4]}$ of waste classification in China, it can be seen that compared with the waste classification actions at the beginning of the 21 st century, the waste classification project in China is gradually becoming legal, systematic and national in the new period, and is becoming an important part of the current ecological civilization construction in China, with great social and economic benefits. However, based on the unsuccessful practical process of waste classification in China in the past, the implementation of nationwide waste classification in the new period will inevitably face enormous risks and challenges, and the following considerations are put forward.

\subsection{Full coverage of infrastructure related to waste sorting}

Efforts should be made to achieve full coverage of infrastructure related to urban garbage classification, and full-time and part-time personnel for garbage classification work should be provided to improve the utilization rate of classification facilities. Nowadays, only some cities have started to strictly control the management of garbage classification, but most areas have not taken relevant measures to promote the classification of urban garbage. As far as we are concerned, there are many crowded places such as communities, schools, stations, etc., which are not equipped with systematic garbage sorting facilities, which is an urgent problem to be solved. As far as the community is concerned, the community is the place where everyone lives, where many families gather, and the family is one of the main places that produce municipal solid waste. It is very necessary to put facilities for garbage sorting in the community and allocate relevant personnel. However, in many cities where garbage sorting control has been carried out, the main force for garbage sorting is the supervisor, which is provided by each community itself. There are many problems, such as uneven quality level of personnel, unstable efficiency and so on. Therefore, it is suggested that the waste sorting office in each community should recruit a group of special management members of waste sorting to form a team to supervise and control the waste sorting work in the community. Is composed of sanitation workers, unified training, unified management, unified inspection and assessment.

\subsection{Improve people's overall awareness of civilization}

Compared with western developed countries, the original waste sorting work in China is not very successful. Apart from the unscientific waste sorting and inadequate organization and coordination of government departments, to a certain extent, it is because ordinary people's civilization and social awareness are not in place, resulting in people's unwillingness to spend more time and capital on more detailed waste treatment in the process of waste sorting, thus failing to achieve the expected social effect. In recent years, China has actively promoted the pace of spiritual civilization construction throughout the country, and the civilization degree of ordinary people has been improved to a certain extent, and citizens' awareness has been strengthened. People have gradually paid attention to ecological environment protection and actively participated in social public welfare undertakings. At the end of 2019, garbage classification was successfully selected as "Top Ten Popular Words in Chinese Media in 2019", which fully indicated that the social recognition of garbage classification among the people was greatly improved, which provided a good spiritual foundation for the effective implementation of garbage classification. Therefore, in the implementation of garbage classification, government agencies should continue to actively publicize the great significance of garbage classification to ecological environment protection and effective utilization of resources through various media such as television, radio, newspapers and internet, actively encourage and guide ordinary people to participate in domestic garbage classification, make green, low-carbon and public welfare become the life pursuit of ordinary people, actively practice green lifestyle, further stimulate people's social awareness and civic responsibility, and let most people independently participate in the process of garbage classification.

\subsection{Implement effective incentive and governance measures}

From the existing policy orientation of waste sorting introduced in various places, it is more disciplinary measures under administrative instructions, but lacks corresponding incentive mechanism. For example, Shanghai, which took the lead in implementing waste sorting, emphasized in its action plan that ordinary people would be fined by 200 yuan for violating the measures of waste sorting, but there was no certain incentive policy for those people who could take the initiative to implement waste sorting. From the perspective of the implementation effect of a policy, incentive mechanism is usually more conducive to achieving the final socio-economic effect than disciplinary mechanism. Therefore, in the specific implementation process of garbage classification in various places, a number of reasonable and effective incentive policies can be formulated for different implementation subjects at different levels, so that 
different incentives can be implemented for institutions and individuals, thus achieving the expected social and economic effects. For ordinary people ${ }^{[5]}$, we can try to set up a "green environmental protection account" for residents, and make use of the existing Internet information technology, so that ordinary people's conscious compliance behavior can be closely linked with personal credit and social welfare, so that ordinary people can continuously improve their personal credit rating and increase social benefits while actively cooperating with garbage sorting.

\subsection{Play the important role of social private capital}

Garbage classification is a systematic project ${ }^{[6]}$ involving the whole people, involving the government, enterprises and individuals. The government's role is mainly reflected in scientific decision-making and guidance and coordination, while the individual's role is reflected in the active cooperation of citizen's responsibility and consciousness. The role of enterprises is reflected in the concrete implementation and operation process of waste sorting. In the past, China's waste sorting history taught that waste sorting engineering was regarded as a social and livelihood behavior too much. As a public good, the government was in a dominant position in all aspects of waste sorting, and failed to give full play to the role of social capital, which finally led to a relative shortage of public funds, which made it impossible to effectively implement scientific waste sorting. At present, China's waste sorting project has been fully launched in the new period. To get rid of the original dilemma, it is necessary to actively play the decisive role of the market, promote more private social capital to enter the link of waste sorting operation, and let social capital play its due role, thus reducing the overall social cost and improving social efficiency.

\section{Conclusion}

By summarizing the historical lessons of waste classification in China, China has made some progress in waste classification in the new period, but it is still in a lagging state. Therefore, China should fully learn from the successful experience of foreign countries in waste classification management, effectively solve the deficiencies in waste classification according to China's national conditions and its own situation, and gradually make the waste classification project legal, systematic and universal in the future practice process of waste classification. In addition, we should improve the waste classification technology, infrastructure, publicity activities, personnel literacy, etc, so as to further enhance the effect of waste classification management, realize rational use of resources, and reduce environmental pollution.

\section{Acknowledgement}

This work was sponsored in part by Tianjin Science and technology major special projects and engineering projects (18ZXSZSF00090), Ministry of Education Humanities and Social Sciences Research Planning Fund (18YJA630121), Tianjin Key R\&D Plan Achievements Transformation Relay Support Project (18YFJLCG00140), Tianjin Municipal Education Commission Social Science Major Project (2018JWZD33), Tianjin Science and Technology Major Special Project and Engineering Project (17ZXSTSF00020), Research and development and system integration application of "Internet +" sudden water environmental safety accident monitoring and early warning technology (19JCTPJC57100), Tianjin "Project + Team" key training special project (BIM-based digital twin building intelligent simulation and operation and maintenance management). Qingdao City Yang Industrial Park supports the creation of characteristic carriers to promote small and medium-sized enterprises innovation and entrepreneurship upgrading projects (Qingdao Rail Transit Intelligent Green Simulation and Digital Simulation Center).

\section{References}

1. S. Li, Huazhong University of Science and Technology. (2013)

2. Y. Zheng, Economic Research Guide. 6 144-145 (2009)

3. R. Yuan, Y. Zhi, Mass Standardization. 5 84-86 (2020)

4. Y. Yu, Y. Wu, Journal of China University of Geosciences (Social Science Edition), 3 25-28 (2003)

5. T. Wang, H. Huang, C. Zhu, Y. Ying, J. Yang, Operation and Management. 8 100-104 (2020)

6. W. Xi, Environmental Hygiene Engineering, 2 23$24+28$ (2007) 